\title{
Posts Characterization and User Engagement: A Preliminary Study on a Mental Health Facebook Page in New Zealand
}

\author{
Anushia Inthiran, University of Canterbury, Christchurch, New Zealand \\ (iD) https://orcid.org/0000-0002-7691-0890
}

\begin{abstract}
Many health organizations use Facebook as a platform to engage with users. This has resulted in many research studies conducted on this platform. One popular type of research study is to characterize posts and measure user engagement levels. In this study, 100 posts on the Mental Health Foundation of New Zealand Facebook page were analyzed for this purpose. A mixed method approach was used. Quantitative descriptive statistics was used to analyze levels of engagement whilst qualitative content analysis was used to characterize posts into themes. Preliminary results indicate most posts fit in the awareness theme followed by the campaign theme. High levels of user engagements were observed for posts related to the awareness and other themes. Results of this study make the suggestion for the implementation of intervention type awareness posts. A recommendation is also to made that the awareness posts promote mental health education and communication. This research study adds new knowledge to the area of posts characterization and user engagement levels on a mental health Facebook page.
\end{abstract}

\section{KEYWORDS}

Facebook, Information Post, Mental Health, Themes, User Engagement

\section{INTRODUCTION}

Across the globe, no less than 792 million people have suffered from mental illness (Ritchie \& Roser, 2018) with this number projected to swell. The World Health Organization (WHO) indicates that mental health is one of the most neglected areas of public health (World Health Organization, 2020). Between low to middle-income countries, more than $75 \%$ of people with mental health do not have access to treatment (WHO, 2020). Sadly, many mental health patients report having emotional and mental trauma; for example, in the United Kingdom (UK), 70\% of people affected by mental illness report having experienced discriminatory and prejudicial behavior (Torgovnick, 2008). Many also suffer from widespread human rights abuses (WHO, 2020).

Importantly, mental disorders have serious economic consequences. In 2010, no less than US\$ 800 billion was lost in terms of economic output due to mental health issues. By 2030, this figure is predicted to double (Chamber, 2010). As a developed country, New Zealand (NZ) faces many challenges with mental health (King, 2017; McConnel, 2016; Close, 2016; McCool, 2006). Data published in 2012 indicate that NZ had the highest rate of suicide among males aged 15-19 (Clark, 
2013). Additionally, suicide accounts for approximately one quarter of all deaths of New Zealanders aged between 15 and 24 years (Office of the Prime Minister's Science Advisory Committee, 2011). This makes NZ the country with the highest rate of teen suicide in the developed world (McConnel, 2016). Based on data collected by the NZ Ministry of Health (2013), 47\% New Zealanders will generally suffer a common mental illness in their lifetime. In 2019, results of a survey indicate that $23 \%$ of NZ youth report symptoms of depression with $6 \%$ attempting suicide in the last 12 months (Menzies, Gluckman \& Poulton, 2020). Moreover, access to mental health services among youths was persistently inequitable and worsening (Menzies, et al., 2020). Apparently, NZ mental health system is a letdown and has somewhat contributed to the regressive state of mental health in the country (King, 2017, Close, 2016; McCool, 2006), thereby, making mental health an important conversational agenda in NZ. To this end, mental health organizations have turned to Facebook to reach out, engage and provide information to health consumers (AlMamun, Ibrahim \& Turin, 2015; Hernandez, 2013; Park, Rodgers \& Stemmle, 2013).

Facebook is the preferred social network (SN) platform due to its increasing popularity (Perrin, 2015), high engagement rates (Duggan, Ellison, Lampe, Lenhart, \& Madden, 2016), number of active users (Facebook) and ubiquity (Zhang, He \& Sang, 2013). Also, Facebook pages have been viewed as a reliable source to obtain peer support as well as to share and receive information from fellow health consumers (Nazzal, Rabee, Ba' ara \& Bert, 2018; Zhang, et al., 2013; Bender, Jimenez-Marroquinn $\&$ Jadad, 2013). More recently, researchers have analyzed data on mental health outcomes resulting from using mental health-based Facebook pages (Frost \& Rickwood, 2017). Yet, no study on post characterization and user engagement levels vis-à-vis the mental health Facebook pages has emerged even though user engagement levels and post characterization have been studied for other health issues such as hypertension (AlMamun, et al., 2015), diabetes (AlQarni, Yunus \& Househ, 2016; Zhang, et al., 2013) and cancer (Biancovilli, Picaco \& Jurberg, 2017; Bender, et al., 2013; Farmer, Bruckner, Cool, \& Hearing, 2009).

In light of the above, this research aims to address the existing knowledge gap with the focus on Facebook mental health and wellbeing webpages. The rest of this paper is organized as follows. Section 2, the next section, provides the background and overviews the extant literature relating to use of Facebook webpages. Section 3 discusses the study methodology while Section 4 concentrates on mix-method analysis and results. Section 5 will then shift focus into discussing the implications of key findings while Section 6 concludes the paper with insights into potential study limitations and future research directions.

\section{BACKGROUND}

Prior research on Facebook health webpages pertaining to mental health has been far ranging. Nazzal, et al. (2018) studied the effects of Facebook on physical and mental health while Farahania, Kazemi, Aghamohamadib, Bakthirar \& Ansarid (2011) examined mental health indices of students who use Facebook. Angie (2014) described the impact of using Facebook on self-esteem and mental health whereas Brailovskaia \& Margraf (2016) conducted a comparison study on how personality traits, mental health variables compared between Facebook v. non-Facebook users.

Compared to other health issues, mental health is a 'silent,' but equally important and potentially threatening condition vis-à-vis other types of illnesses. Hence, it is important to know to how Facebook mental health pages engage with users (post characterization) and how users engage with mental health Facebook pages (user engagement). When post characterization is known, it provides the ability for raising health awareness among users and the ability to develop interventions for health information, education, and communication (AlMamun, et al., 2015). Similarly, user engagement levels provide information on how social and emotional transformation and appraisal support takes place (Zhang, et al., 2013). It also explains how companionship may be cultivated implicitly over a health issue 
(Zhang, et al., 2013). As we move in the direction of Health 2.0 it is important to understand how users engage with these Facebook posts (Guistini, Ali, Fraser \& Boulos, 2018; Kordzadeh \& Warren, 2013)

The Mental Health Foundation of New Zealand (MHFNZ) Facebook's page is selected for this research as the author is based in NZ. Given the deteriorating state of mental health in NZ, the proposed study would also be timely. While there are other mental health-based Facebook pages in NZ such as Anxiety New Zealand Trust, Mental Health Awareness and Support Group New Zealand, Mental Health New Zealand Aotearoa, Mental Health Advocacy and Peer Support Group, the MHFNZ Facebook page was specifically selected as it is the oldest non-profit mental healthbased organization in NZ.

A charitable trust with a governing body that conducts diverse and expansive work in relation to mental health and wellbeing, the MHFNZ was established in 1977 from the proceeds of a telethon to provide free information, training and being an advocate for policies and services to support people in need alongside their families and friends (Mental Health Foundation, 2020). The governing board members of the foundation comprises experts in their field and are professionals who collectively guide the direction of the MHFNZ (Mental Health Foundation, 2020). The MHFNZ also has a board of trustees comprising experts in the mental health, legal and financial field. Members of the board of trustees consists of representatives from a wide geographic reach (Mental Health Foundation, 2020).

The MHFNZ principles and values are based on two core documents: (a) Te Tiriti o Waitangi (The Treaty of Waitangi); and (b) the Ottawa Charter (Mental Health Foundation, 2020). The MHFNZ's overarching goal is to nurture a society free from discrimination, where all people can enjoy positive mental health and wellbeing (Mental Health Foundation, 2020). It is funded via donations, grants and contract income (Mental Health Foundation, 2020) and MHFNZ maintains a website, a Facebook page, a Twitter link and a YouTube channel with the Facebook page having the highest number of followers (Facebook with 50,709 followers, Twitter with 6993 followers, and YouTube with 537).

Accordingly, the Facebook page was selected for this study as it had a higher number of followers vis-à-vis other MHFNZ social media platforms.

\subsection{Focus of Current Study}

At this point, a brief explanation is warranted so as to understand the selection of prior research available for review. First, the focus of this research is on Facebook health pages rather than other SN platforms as these platforms are setup for different purposes (Egan, 2017). As well, only past studies conducted on a health-based Facebook page have been selected for review so as to provide contextualize comparison. As there are many Facebook pages setup for non-health purposes, the user engagement levels and post characterizations on these pages would be dissimilar; for example, a business Facebook page post characterization and user engagement levels would need to be translated into an intention of positive impact or the likelihood to purchase (Lee \& Hong 2016; Xie \& Lee, 2015).

Given the focus of this research study is on a single Facebook page dealing with a single health condition, bodies of literature that dealt with multiple health conditions on a single page have also been excluded. Taking this stand allows for discussion, analysis and understanding of user engagement levels and post characterization of a particular health issue. In addition, research pertaining to post characterization and user engagement levels on a single Facebook page dealing with multiple health issues would not provide an equal representation of all health issues covered within the page (Bhattacharya, Srinivasan \& Polgreen, 2017; Syn, 2015).

\subsection{Prior Research}

For all intent and purpose, a literature search was conducted via Google search between February 2017 and December 2017 using keywords such as 'information posts Facebook health page' and 'user engagement Facebook health page'. The search was performed over these dates as they coincided with the data collection stage and the writing of this paper. Search terms used during the search process were specific and contextualized to minimize the inclusion of unrelated literature. 
Search results indicate that research selected mainly fit into two categories. The first encompasses studies conducted on multiple health-based Facebook pages for the same health condition (AlMamun, et al., 2015; Angie, 2014; Bender, et al., 2013). The second category comprises studies performed on a single Facebook page discussing multiple health conditions (Card, Lachowsky \& Hawkins, 2018, Bhattacharya, et al., 2017; Syn, 2015). Based on the inclusion-exclusion criteria of the literature search, the following specific studies were then shortlisted for analysis: Baincovili, et al. (2017); AlQarni, et al. (2016); AlMamun, et al. (2015); Zhang, et al. (2013); Bender, et al. (2013); and Farmer et al. (2009).

It should be noted that no studies for post characterization and user engagements levels for a mental health Facebook page has been found; nevertheless, much insight on post characterization and user engagements levels may be gleaned from non-mental health Facebook pages. Thus, these non-mental health-based studies are included to provide a view on post characterization and user engagement levels. These research studies have been used to set the scene and for discussion.

Specifically, prior research indicates that Facebook pages that relate to hypertension had the highest number of posts for the following themes: awareness-creation, providing support for patients and caregivers and disease experience sharing (AlMamun, et al., 2015). There were very few posts that relate to the fundraising, product promotion, research and health professional groups theme (AlMamun, et al., 2015). Results of a similar study pertaining to Arabic Facebook pages on diabetes indicate that posts fell into the following top three themes: sharing personal experience, raising awareness and providing spiritual support (AlQarni, et al., 2016). There were limited number of posts in relation to the research and education theme (AlQarni, et al., 2016). These findings imply that there are similar popular themes across connecting research domains. It is thus postulated that there are popular themes across Facebook health pages. Themes in relation to fund raising, awareness creation, sharing of personal experience and disease sharing experience emerge as the largely popular themes. This indicates similarity in themes regardless of the disease type being investigated.

On diabetes research, results indicate that the highest number of posts on a diabetic Facebook page were related to giving and receiving information, expressing and seeking emotional support and community building (Zhang, et al., 2013). The themes presented in (Zhang, et al., 2013) indicate dissimilarity to the study on diabetics by (AlQarni, et al., 2016). Whilst Zhang, et al. (2013) indicate most posts were related to giving and receiving information, expressing and seeking emotional support and community building theme, AlQarni, et al. (2016) indicate the top themes being related to sharing of personal experience, raising awareness and providing spiritual support. Given the discrepancy of these two studies in light of their top themes identified, what might explain their equivocal findings? A possible reason could be attributed to the origin of the Facebook page. In (AlQarni, et al., 2016), the Facebook pages were written in Arabic, thereby catering to an Arabic literate audience; conversely, the Zhang, et al. (2013) study has their Facebook pages written in English. Thus, it may not be wrong to suggest that the language used, the affinity/locality characteristics of the Facebook page and the type of visitors to these pages can all influence emerging themes on the Facebook page.

With breast cancer Facebook pages, the majority of posts relates to the fundraising theme (Bender, et al., 2013) with minimal posts relating to the supportive care theme. Results of a 2017 study analyzing posts of three Brazilian-based breast cancer Facebook pages indicate that most posts relate to providing testimony and for the purpose of solidarity with minimal posts relating to the beauty and risk factors theme (Baincovili, et al., 2017). Results of the aforementioned lines of research indicate simply that there can be a difference in emphasizing various themes depending on the type of disease focus. Interestingly, for the illness malignant neoplasms (which is a type of cancer), the highest number of posts were related to the patient and caregiver support theme whilst the fundraising theme had the least number of posts (Farmer, et al., 2009). This indicates that there is a possibility of different theme popularity across different types of sub-illnesses maintained by different health organizations.

Ultimately, characterizing themes of different Facebook pages is complex as these themes may be dependent on different types of audience, languages being used to construct these pages, and 
diseases being explored, among other things. The diabetics Facebook page popularity themes were dissimilar for pages in the English and Arabic language (AlQarni, et al., 2016 v. Zhang, et al., 2013). However, themes are common with hypertension for Arabic diabetics Facebook pages (AlQarni, et al., 2016 v. AlMamun, et al., 2015). Breast cancer Facebook pages themes are on fundraising in contrast to diabetics or hypertension page themes which focused on awareness, providing support, sharing personal experience and giving and receiving information (AlQarni, et al., 2016, AlMamin, et al., 2015, Bender, et al., 2013; Zhang, et al., 2013). The supportive care theme has the lowest number of posts for breast cancer Facebook pages (Bender, et al., 2013) whereas the Brazilian breast cancer Facebook posts have themes that are mostly based on the testimony theme (Biancovilli, et al., 2017). Finally, it is interesting to note that for malignant neoplasm, there are more posts for the support theme in comparison to the fundraising theme (Farmer, et al., 2009).

Whilst there is information on post characterization on non-mental health Facebook pages, the situation for mental health Facebook pages is unknown - a knowledge gap waiting to be filled here, resulting in the following unanswered questions: (a) What type of themes emerge for post characterization on a mental health Facebook page? And (b) Will these themes be the same or dissimilar vis-à-vis themes on non-mental health Facebook pages? Moreover, whilst there is information in relation to post characterization; information related to user engagement is scarce. To date, the only study that provided information in relation to user engagement levels for post characterization is AlQarni, et al. (2016). Results of this research indicate that for Arabic diabetes Facebook pages, themes concerning experience sharing, support for patients and caregivers and raising awareness achieved having high user engagement whereas themes related to service promotion and sharing of recipes have the lowest level of engagement (AlQarni, et al., 2016).

Altogether, the critical takeaway lesson here is that there is no information in relation to user level engagement on a mental health Facebook page. Thus, this study attempts to fill such a knowledge gap. Table 1 summarizes the key themes and user engagement activity based on our literature review. More specifically, the approach taken in this study is to characterize posts on the MHFNZ's Facebook page and to measure user engagement levels against each post. It is postulated that information on user engagement levels is important as it provides information to the owners of the page on what types of information attracts the attention of members of the group.

Importantly, the characterization of posts describes the owner's effort and initiative in performing cooperative social responsibility. As such, the aim of this research study is to describe the Facebook posts as posted by the MHFNZ based on theme names and to measure user engagement levels for each theme. The research questions to be addressed include:

(i) What type of posts based on themes are available on the Facebook page? and

(ii) How much user engagement levels do these posts garner?

\section{STUDY METHODOLOGY}

As of February 2017, the MHFNZ Facebook page had a total of 18,531 likes and 18,125 followers. As part of this preliminary study, a total of 100 posts were reviewed beginning $28^{\text {th }}$ of February 2017.

A key reason in choosing this date is that it denotes the start of the study data collection phase. Posts during this time, which coincided with several key occurrences within the mental health scene in NZ, were reviewed. The first was the publication of the New Zealand's Mental Health and addiction services report. Results of this report indicate that young people had the longest wait times for mental health services of any population group and that young people are less likely than adults to be followed up within 7 days of being discharged from an inpatient unit (Health \& Disability Commission, 2017). Additionally, the same report indicates that none of the District Health Boards have met the target of achieving a transition plan for patients after being discharged (Health \& Disability Commission, 2019). A second reason for this timeline selection is the release of the country's mental health budget, 
Table 1. Summary of Themes and User Engagement Activity

\begin{tabular}{|c|c|c|c|c|c|}
\hline \multirow{2}{*}{$\begin{array}{l}\text { Disease } \\
\text { Type }\end{array}$} & \multicolumn{2}{|r|}{ Theme } & \multirow{2}{*}{\multicolumn{2}{|c|}{ User Engagement }} & \multirow{2}{*}{$\begin{array}{l}\text { Research } \\
\text { Study }\end{array}$} \\
\hline & $\begin{array}{l}\text { Most } \\
\text { Popular }\end{array}$ & $\begin{array}{l}\text { Least } \\
\text { Popular }\end{array}$ & & & \\
\hline $\begin{array}{l}\text { Hyper- } \\
\text { tension }\end{array}$ & $\begin{array}{l}\text { Awareness, } \\
\text { Support and } \\
\text { Disease } \\
\text { experience } \\
\text { sharing }\end{array}$ & $\begin{array}{l}\text { Fundraising, } \\
\text { Product } \\
\text { promotion and } \\
\text { Research } \\
\text { Health } \\
\text { professional group }\end{array}$ & Unknown & & $\begin{array}{l}\text { AlMamun, } \\
\text { Ibrahim \& Turin } \\
\text { (2015) }\end{array}$ \\
\hline \multirow[t]{2}{*}{ Diabetics } & \multirow[b]{2}{*}{$\begin{array}{l}\quad \text { Sharing } \\
\text { personal } \\
\text { experience, } \\
\text { Raising } \\
\text { awareness and } \\
\text { Providing } \\
\text { spiritual support }\end{array}$} & \multirow[b]{2}{*}{$\begin{array}{l}\text { Research and } \\
\text { Educational, } \\
\text { Support } \\
\text { for patient and } \\
\text { caregivers, } \\
\text { Services and } \\
\text { Promotion and } \\
\text { Sharing } \\
\text { recipes }\end{array}$} & High & Low & \multirow{2}{*}{$\begin{array}{l}\text { AlQarni, Yunus } \\
\& \text { Househ (2016) }\end{array}$} \\
\hline & & & $\begin{array}{l}\text { Experience } \\
\text { Sharing, Support } \\
\text { for patients } \\
\text { and caregivers } \\
\text { and raising } \\
\text { awareness }\end{array}$ & $\begin{array}{l}\text { Services } \\
\text { and promotion } \\
\text { and } \\
\text { Recipes } \\
\text { sharing }\end{array}$ & \\
\hline Diabetics & $\begin{array}{l}\quad \text { Giving } \\
\text { and receiving } \\
\text { information, } \\
\quad \text { Expressing } \\
\text { and seeking } \\
\text { emotional } \\
\text { support and } \\
\quad \text { Community } \\
\text { building }\end{array}$ & Unknown & \multicolumn{2}{|l|}{ Unknown } & $\begin{array}{l}\text { Zhang, He \& } \\
\text { Song (2013) }\end{array}$ \\
\hline $\begin{array}{l}\text { Breast } \\
\text { Cancer }\end{array}$ & Fundraising & $\begin{array}{l}\text { Supportive } \\
\text { care }\end{array}$ & \multicolumn{2}{|l|}{ Unknown } & $\begin{array}{l}\text { Bender, } \\
\text { Jimenez, Marroquinn } \\
\text { \& Jadad (2013) }\end{array}$ \\
\hline $\begin{array}{l}\text { Malignant } \\
\text { Neoplasma }\end{array}$ & $\begin{array}{r}\text { Patient and } \\
\text { caregiver support }\end{array}$ & Fundraising & \multicolumn{2}{|l|}{ Unknown } & $\begin{array}{l}\quad \text { Farmer, } \\
\text { Bruckner, Cool \& } \\
\text { Hearing (2009) }\end{array}$ \\
\hline $\begin{array}{l}\text { Breast } \\
\text { cancer }\end{array}$ & $\begin{array}{ll} & \text { Testimonies } \\
\text { and } & \\
& \text { Solidarity }\end{array}$ & $\begin{array}{l}\text { Beauty and } \\
\text { Risk Factors }\end{array}$ & \multicolumn{2}{|l|}{ Unknown } & $\begin{array}{l}\text { Baincovili, } \\
\text { Picanco \& Jurberg } \\
\text { (2017) }\end{array}$ \\
\hline
\end{tabular}

which has been labeled as distressing given that the health funding budget was short by $\$ 300$ million (Wiggins, 2017).

In this preliminary study, only 100 posts were analyzed due to limited available resources (e.g., time, funding, and research assistance). To provide a comparison, Zhang, et al. (2013) analyzed 154 posts with a total of 1550 user level engagements. The current study has been conducted via a mixedmethod approach; specifically, the conventional qualitative content analysis was used to develop themes for post characterization and a descriptive quantitative analysis was performed to analyze post characterization and user engagement levels.

The decision to stop the analysis at 100 posts was made to provide preliminary information on post characterization and user engagement levels. Interestingly, within the 100 posts, a total of 17,020 user level engagements were observed (likes, comments, and sharing). 100 posts were reached to include postings dated up to and including those on the $15^{\text {th }}$ of May 2017. This means that the live data collection took place, continued past the $28^{\text {th }}$ of February and were revisited to update user engagement levels throughout the study period. All post available on this Facebook page can only be 
posted by MHFNZ. Members of the page are only able to comment, like or share posts as posted by MHFNZ. Actually, the Facebook page is a public page that anyone can like, follow, send a message or invite friends to like the page.

As this Facebook page is setup as a charity, it is possible also to make a donation to the foundation. The About section of the page contains contact details including an email address, a phone number, a website address and details of the opening hours of the MHFNZ. The mental health foundation of New Zealand's Facebook page is available at the following link:

https://www.facebook.com/mentalhealthfoundationNZ/.

\subsection{Data Collection}

Prior to starting the data collection, the author wanted to determine and understand the level of activity in this page. To facilitate this, the author followed the page for three (3) weeks, beginning the $1^{\text {st }}$ of February 2017.

During this stage, the author observed the number of posts put up by MHFNZ and user engagement levels of these posts throughout the month of January 2017. Manual snapshots of posts and user engagement levels were observed. As a result of this observation process, the author found that there was at least 1 post per day by the MHFNZ and each post had a good level of user engagement with followers reacting to the posts by sharing, commenting and using the typical emoticons (L-like, LV-love, H-haha, A-angry, S-sad, W-wow). At a minimum, each post would have at least 15 user engagement interactions (liking, sharing, and commenting).

During the three (3) weeks of observation, never a day had gone by without new posts appearing (observed time was based on Facebook's time stamp for each post) and never a day passed without observing active user engagement levels appearing for a post. Zhang, et al., (2013) applied this same method of observation in their research; thus, the approach taken by the author in this study is in keeping up with similar practices of prior researchers.

\subsection{Data Analysis}

\subsubsection{Characterization of Posts}

For characterizing posts, two approaches were deployed. The first was based on utilizing themes drawn from previous work (Biancovilli, et al., 2017; AlQarni, et al., 2016; AlMamun, et al., 2015; Zhang, et al., 2013; Bender, et al., 2013; Farmer, et al., 2009). The selection of previous literature was based on studies having a common research aim, which is to characterized information post on non-mental health Facebook pages. As such, instead of creating new themes, themes drawn from existing work were used. The only criteria of using a theme is that the theme must appear in all the selected work being studied. This led to the following first set of six (6) themes applicable for characterizing the MHFNZ posts: (1) support; (2) awareness; (3) fundraising; (4) campaign; (5) advertising, (6) testimonial.

On completing this stage, the author realized that some of the posts did not fit into the aforementioned six (6) themes. As such, new themes had to be created, which dictated the second approach. In this approach, the open coding method was used to categorize posts that were not accommodated by the various aforementioned themes. Since prior research has not been based on any mental health Facebook page, it is expected that these new themes would emerge when analyzing posts on a mental health Facebook page. All existing posts that did not fit in the six (6) themes drawn from prior work were classified into newer themes via the second approach.

Accordingly, a conventional qualitative content analysis technique was used to create the codes and themes in the second approach (Zhang \& Wildemuth, 2005). A master list of codes was first created based on induction. These codes were then revisited after evaluating every third post. These codes were further reduced to themes using the constant comparative method. The conventional qualitative content and constant comparative method together allows for the exploration of meaning and for themes and categories to emerge vis-à-vis the embedded data (Zhang \& Wildermuth, 2005). 
On the basis of this second approach, four (4) new themes labeled as theme 7-10 were created. These themes include: (7) call to action (8) job posting, (9) acknowledgement of donation, and (10) others. In an effort to increase the internal validity of these newer themes, an independent researcher was asked to check that these emerging themes were appropriately named and created in a reasonable and scientifically correct manner. Thus, a comprehensive theme scheme was formed from the ten (10) themes identified here (theme 1-10), which were used to characterize the MHFNZ posts. Each post was coded into one theme to avoid issues when analyzing user engagements levels. In order to characterize a single post into one theme (and one theme only), the post needs to fit that theme by $80 \%$. This means that both the author and the independent researcher would need to agree that a post must most likely fit int one theme. The same independent researcher, who separately characterized the posts into the appropriate themes, has then to corroborate and iron out any differences in the characterization of all of the studied posts vis-à-vis the author's characterization perspective.

Table 2. Themes and definition

\begin{tabular}{|l|c|}
\hline \multicolumn{1}{|c|}{ Theme Name } & \multicolumn{1}{c|}{ Definition } \\
\hline Support & $\begin{array}{c}\text { Created for informational and emotional needs for family members, } \\
\text { friends and mental health patients (AlMamun, Ibrahim and Turin, 2015) }\end{array}$ \\
\hline Awareness & Bring attention (AlMamun, Ibrahim and Turin, 2015) \\
\hline Fundraising & $\begin{array}{c}\text { Attract financial resources or to make donation (Bender,Jimenez, } \\
\text { Marroquinn and Jadad, 2013) }\end{array}$ \\
\hline Campaign & $\begin{array}{c}\text { To provide information about a specific campaign (AlQarni, Yunus and } \\
\text { Househ, 2016) }\end{array}$ \\
\hline Advertising & \begin{tabular}{c} 
To provide information on other events (Zhang, He and Song, 2013) \\
\hline Testimonial
\end{tabular} \\
\hline Call to action & $\begin{array}{c}\text { Use of people to tell a personal story (Baincovili, Picanco and Jurberg, } \\
\text { Encourage users to undertake specific action }\end{array}$ \\
\hline Job Posting & Job vacancy advertising \\
\hline Acknowledgement of Donation & A note of thanks and appreciation to donors \\
\hline Others & Any other post that does not fit in the categories above \\
\hline
\end{tabular}

Table 2 highlights details of the themes. The details on definition of the first six (6) themes are drawn from prior research whilst the definition for the last four (4) themes has been developed by the author, cross-checked with the independent evaluator (researcher).

\subsubsection{User Engagement}

To measure user engagement, all observed usage of user engagement elements was taken into account. Possible elements of user engagement were clicking on the Share button (Share), clicking on the Comment button (Comment) and the usage of emoticons (L-like, LV-love, H-haha, A-angry, S-sad, W-wow).

Whilst many Facebook users would have their own definition to the meaning of these emoticons, a summary of their definition is provided for background information. Specifically, Like is similar to using thumbs up in the real world; Love, the heart emoticon, is used when you are in love with the post; Haha is a squinchy-eyed grin and is used to represent the action of laughing out loud; Wow is a surprised-face used when something catches you off-guard, whether it be positively or negatively; 
Sad is used when the post gives you sad feelings; and, Angry, the scowling angry face, is a direct reason to use this reaction when it means that this post makes one angry (Duggan et al., 2016).

Values generated for reporting are as given in Table 4, which is discussed and provided in a later section of this paper. These values were obtained from manually counting the number of interactions each post achieved between February 2017 and May 2017. For the comment element, the Facebook provides the number of times a post has been commented upon; therefore, the value as provided by Facebook is used. Yet, Facebook does not provide the value for comments within comments; thus, this value was obtained manually and included in the analysis. For sharing, Facebook provides this value; hence, this value is taken into consideration automatically. As this page does not allow members to post on the wall, this activity is not used as a metric.

\section{STUDY RESULTS}

In this section, the background information on the 100 posts is provided, followed by results on post characterization and user engagement levels.

\subsection{Background Information on Posts}

Posts from $28^{\text {th }}$ of February 2017 up to the $15^{\text {th }}$ of May 2017 may be grouped into three different types: (a) Narrative with accompanying text and image or Narrative posts; (b) Video with accompanying narrative, text or image or Video posts; and (c) Shared posts taken or shared from other sources originated from NZ and International websites or Shared posts.

Among different posts, the highest number of posts consisted of the Narrative whilst the Video made up the least number of posts. MHFNZ usually puts up one daily post. A total of 45 posts were original (not shared or taken from other sources) whilst 55 posts were shared or taken from other sources. Shared posts can originate from NZ and/or International websites. Examples of posts from NZ-originated websites come from the Rolleston College, Massey University Maori Videos, Stuff, the Mental Health Organization, After Suicide New Zealand, All Right, The New Zealand Herald, NewsHub, Radio New Zealand, Like Minds Like Mine and The Spinoff, Mindfulness Education New Zealand, Entertainment Book New Zealand, AllRight, HeadFirst and The Nation. Posts that originated from International-based websites include those from The Huffington Post, Metro.co.uk., The Guardian and the British Broadcasting Corporation (BBC) website. As anticipated, Internationalbased website shared postings were not as many as shared posts originating from NZ-based websites.

\subsection{Post Characterization}

Posts falling under the awareness theme were the highest number of posts being characterized, followed by those grouped under campaign and others. Support, job-posting and acknowledgement of donation themes had the least number of posts. Table 3 details the characterization of posts and their popularity.

In the awareness theme, posts relate largely to providing information on wellbeing, to reduce stigma, to end discrimination against mental illness, the need for psychiatric hospitals, information on prevention of youth suicide and mental health initiatives. Examples of posts in the awareness theme include reducing work stress and creating a better work environment $\left(7^{\text {th }}\right.$ May), providing information on Pause, Breathe, Smile (PBS), New Zealand's only locally developed and researched mindfulness in school programs ( $4^{\text {th }}$ May) and practical tips for coping with a disaster (13 ${ }^{\text {th }}$ April).

Posts in the campaign theme relate to the launch of campaigns such as Day of Silence (silencing the effect of homophobic, biphobic and transphobic bullying, name-calling and harassment), Like Mind, Like Me (public awareness campaign on social inclusion towards people with mental health illness), Take The Load Off (reduce stigma of mental health and discrimination), Family Fun Day (mental health and wellbeing), Mental Health Series Production, Break The Silence (suicide prevention), mental health charity auction, Ride Sunday (support a cause riding for the mental health foundation), 
Table 3. Characterization of posts and popularity

\begin{tabular}{|l|l|}
\hline \multicolumn{1}{|c|}{ Theme Name } & \multicolumn{1}{c|}{ Popularity Percentage (\%) } \\
\hline Awareness & 24 \\
\hline Campaign & 20 \\
\hline Others & 15 \\
\hline Testimonial & 10 \\
\hline Advertising & 9 \\
\hline Fundraising & 7 \\
\hline Call to action & 6 \\
\hline Support & 4 \\
\hline Job posting & 3 \\
\hline Acknowledgement of donation & 2 \\
\hline
\end{tabular}

Pink Shirt Day (stop bullying), a campaign for better mental health education in all NZ schools and the comedy for a cause campaign.

For the testimonial theme, posts relate to personal stories of overcoming stigma associated with mental health and stories in relation to asking for help when there is a propensity to experience mental illness. Specific examples here include a posted article entitled What I Learnt from Opening Up to Family and Friends about Depression ( $7^{\text {th }}$ April), an article where Prince Harry shared his experience coping with the loss of his mother $\left(10^{\text {th }}\right.$ April) and an article on a NZ personality opening up about his experience on mental health and urging people to talk to professionals when help is needed (19 March).

For the advertising theme, posts relate to the launch of a website for family and friends who have suffered a loss from suicide, the promotion of material and resources, mental health webstore, Blake Award Medal winners and the Pod Caster award winner. As for the fundraising theme, posts revolve around the sale of tickets for a fundraising festival and raising money for a bungee jumping activity by a celebrity. Specific examples include a 21 pilots a pop band post signing a ukelele to auction it with the proceeds going to the MFHNZ ( $28^{\text {th }}$ March) and the selling of copies of Entertainment Book (booklets packed with vouchers, discount tickets to attractions in NZ and discounted dining) with the proceeds again going to the MHFNZ ( $23^{\text {rd }}$ April). In the call-to-action category, posts relate to getting people involved in the Day of Silence campaign and for pay equity for mental health support workers, action being taken to assist prison inmates who have been diagnosed with a mental health or substance abuse disorder (26 $6^{\text {th }}$ April) and call for people to support Chasing the Dragon (Adventure race for mental health).

Finally, posts within the support theme relate to a response to Kathy Perry's depression article, gathering support for the GIVE project and to support suicide prevention activities following the suicide of the singer Chester Barrington. Those posts under the job posting theme relate to job vacancy within the mental health foundation. The acknowledgement for donation theme relates to recognizing donors for funding vis-à-vis resource printing. In the others theme, posts touch on the celebration of the Maori New Year, Earth Day, Easter, Happy Friday messages and the registration for a competition.

\subsection{User Engagements}

Table 4 highlights theme names along with user engagement details for analyzing user engagement levels (Note: AoD- Acknowledgement of Donation, Test - Testimonial, Fund=Fundraising). 
For each theme, descriptive quantitative statistics has been reported for subtotals and percentages. These values are presented for the following user engagement elements: (a) sharing; (b) commenting; and (c) interacting with the following emoticons: Likes, Love, Haha, Sad, Angry and Wow. Subtotal values for each individual user engagement level are provided in the last row at the bottom of the table. Total values for all user engagement elements are provided on the extreme right column. From Table 4, it is apparent that the Like emoticon has been used the most, followed by the Share function. The Angry and Wow emoticon have been used the least.

Table 4. User Engagement Based on Themes

\begin{tabular}{|c|c|c|c|c|c|c|c|c|c|c|}
\hline \multicolumn{2}{|c|}{ Theme } & \multirow{2}{*}{$\frac{\text { Share }}{1347}$} & \multirow{2}{*}{$\begin{array}{l}\text { Comment } \\
370\end{array}$} & \multirow{2}{*}{$\begin{array}{c}\text { Like } \\
3657\end{array}$} & \multirow{2}{*}{$\begin{array}{l}\text { Love } \\
434\end{array}$} & \multirow{2}{*}{$\begin{array}{l}\text { Haha } \\
53 \\
8\end{array}$} & \multirow{2}{*}{$\frac{\text { Sad }}{36}$} & \multirow{2}{*}{$\frac{\text { Angry }}{1}$} & \multirow[t]{2}{*}{ Wow } & \multirow{3}{*}{$\begin{array}{c}\text { Total } \\
5898\end{array}$} \\
\hline Awareness & Total & & & & & & & & & \\
\hline & $\%$ & 40.1 & 36.4 & 31.9 & 31.9 & 4.1 & 14.2 & 8.3 & & \\
\hline \multirow[t]{2}{*}{ Campaign } & Total & 219 & 31 & 1253 & 131 & & 6 & & & \multirow[t]{2}{*}{1640} \\
\hline & $\%$ & 6.5 & 3.0 & 11.2 & 9.6 & & 2.2 & & & \\
\hline \multirow[t]{2}{*}{ Others } & Total & 369 & 267 & 1540 & 156 & 10 & 18 & & & \multirow[t]{2}{*}{2124} \\
\hline & $\%$ & 11.0 & 3.0 & 13.8 & 11.4 & 15.8 & 7.1 & & & \\
\hline \multirow[t]{2}{*}{ Test } & Total & 213 & 39 & 1076 & 187 & & 1 & & 1 & \multirow[t]{2}{*}{1517} \\
\hline & $\%$ & 6.8 & 3.8 & 9.6 & 13.7 & & 3.6 & & 33.3 & \\
\hline \multirow[t]{2}{*}{ Advert } & Total & 420 & 47 & 1028 & 1450 & & 1 & & 2 & \multirow[t]{2}{*}{1643} \\
\hline & $\%$ & 12.5 & 4.6 & 9.2 & 10.6 & & 0.3 & & 6.6 & \\
\hline \multirow[t]{2}{*}{ Fund } & Total & 91 & 62 & 696 & 95 & & 29 & & & \multirow[t]{2}{*}{974} \\
\hline & $\%$ & 2.7 & 6.1 & 6.2 & 6.9 & & 11.5 & & & \\
\hline \multirow{2}{*}{$\begin{array}{l}\text { Call to } \\
\text { action }\end{array}$} & Total & 175 & 95 & 792 & 20 & & 14 & 11 & & \multirow[t]{2}{*}{1107} \\
\hline & $\%$ & 5.2 & 9.3 & 6.3 & 1.4 & & 5.5 & 83.3 & & \\
\hline \multirow[t]{2}{*}{ Support } & Total & 483 & 95 & 1033 & 180 & & 138 & & & \multirow[t]{2}{*}{1929} \\
\hline & $\%$ & 14.4 & 9.3 & 9.2 & 13.2 & & 4.7 & & & \\
\hline \multirow[t]{2}{*}{ Job Posting } & Total & 17 & 8 & 110 & & & & & & \multirow[t]{2}{*}{135} \\
\hline & $\%$ & 0.5 & 0.7 & 0.9 & & & & & & \\
\hline \multirow[t]{2}{*}{ AoD } & Total & 1 & 1 & 50 & 4 & & & & & \multirow[t]{2}{*}{56} \\
\hline & $\%$ & 0.02 & 0.09 & 0.4 & 0.2 & & & & & \\
\hline \multicolumn{2}{|l|}{ Total } & 3353 & 1015 & 11235 & 1352 & 63 & 243 & 12 & 3 & 17022 \\
\hline
\end{tabular}

Not surprisingly, the highest number of user engagement elements can be associated to the awareness theme. This is followed by the others and support theme. The job posting and acknowledgement of donation themes have the lowest level of user engagement. The call-to-action theme has the highest number of Angry emoticons linked to it whilst the advertising theme has the highest number of Wow emoticons associated with it. Posts that fell in the others theme relate to Earth Day celebration, Happy Easter message, resources available, Happy Friday messages, Do what you need to be happy message, the application for podcasts and information on an award presentation ceremony. Finally, the others theme has posts that did not directly relate to mental health although it has the second highest level of user engagement. 
Interestingly, the Angry emoticon has been used for the call-to-action and awareness theme. Callto-action has the highest number of angry emoticons associated with it; upon further investigation, it is noted that whilst some members have been engaged with the posts using the Angry emoticon, others used the Like and Love emoticon for the same posts. A possible explanation such and this observation will now be discussed as given in the section below.

\section{DISCUSSION \& IMPLICATIONS}

This study, which has been conducted on the NZMHF Facebook page, indicates that most of the posts fell under the awareness theme (24\%), followed by the campaign theme (20\%). Previous work in this area has indicated that the awareness theme was also a popular theme for illnesses such as hypertension and diabetics (AlQarni, et al., 2016; AlMamun, et al., 2015), thereby confirming and validating prior research findings.

Whilst results of this study indicate campaign has been the next popular theme, previous research did not show the same result (e.g., AlQarni, et al., 2016; AlMamun, et al., 2015; Zhang, et al., 2013; Farmer, et al., 2009). This interesting finding needs to be explained. It is possible to suggest that campaign is a popular and necessary theme within the mental health realm but possibly not for other health conditions. The rationalization is that having campaigns within the mental health realm is critical and it has the ability to reduce stigma (Sampogna, et al., 2017) and discrimination (Baker, Farmer \& Winstley, 2017).

Stigma and discrimination may not be apparent nor even relevant with health conditions such as hypertension, diabetics and/or cancer, but it certainly plays a key role for mental health. Thus, campaign is found to be an important theme in this mental health Facebook page investigation.

Notwithstanding, this does not imply that non-mental health conditions should ignore the campaigns theme. In fact, having more posts in relation to campaigns could likely reduce or prevent health conditions associated with diabetics and hypertension; for example, coming up with a healthy lifestyle living campaign or mobile-driven fitness campaign for diabetics and hypertension health pages could have the potential of assisting a significant number of health patients with these health conditions to stay healthy and safe.

\subsection{Themes Popularity \& User Engagements}

Previous research indicates fundraising as a popular theme for breast cancer pages (Bender, et al., 2013) but not in the case of malignant neoplasma (Farmer, et al., 2009) nor is it for hypertension (AlMamun, et al., 2015). This suggests that popularity of themes differs based on different concentration of illness conditions. Such an observation will require deeper analysis. Even so, results of this study indicate that fundraising is not perceived as a popular theme on the mental health Facebook page. One reason for the low number of fundraising posts could be attributed to the difficulty in creating and launching a suitable mental health fundraising event (Goldenberg, 2016).

Shifting focus, it is found that the support theme has been popular for diabetics and malignant neoplasma (Angie, 2014; Zhang, et al., 2013) but not a popular theme for breast cancer. Results of this study indicate that the support theme has also not been seen as a popular theme on the mental health Facebook page. Notably, the MHFNZ Facebook page support posts have been tagged to events that relate to mental health challenges or issues such as suicide of a celebrity or supporting celebrities who share their battles with mental health issues. However, on non-mental health Facebook pages, the support themed pages mainly contained information for patients and caregivers (e.g., AlMamum, et al., 2015). Herein lies another key difference between the type of post for the same theme on mental health v. non-mental health Facebook pages.

Results of this study indicate that there are themes which emerged from this research that did not appear in other earlier studies. These themes include call-to-action, job posting, and acknowledgement of donation - all of which has not been shown on non-mental health Facebook pages. Nonetheless, 
the number of posts on the MHFNZ page for these themes has only been minimal, that is, $6 \%, 3 \%$, and $2 \%$ respectively.

First, the call-to-action theme encourages support for campaigns to be run. It has been a popular theme for the MHFNZ page but not for Facebook pages of other health conditions. A rationale for this may be that it may be more important to 'act' on mental health issues which are non-symptomatic; hence, if left undiagnosed or untreated for a long time, it may result in death (Baker, et al., 2017). Also, the campaign theme has received important attention in the MHFNZ page; even then, the posts related to this theme did not garner much user engagement. Perhaps the campaigns have not been appealing to members or that the mental health campaigns have been targeted only to specific groups of audience, a finding that requires further investigation.

Another interesting finding is that whilst the others theme was not focused on any mental health issues per se, it garnered more user engagement in comparison to campaign. This suggests that members appreciated non-mental health posts are willing to engage in these types of posts as well. Thus, to answer the first research question (i) what type of posts based on themes are available on a mental health Facebook page? Our finding appears to be that the top two (2) themes identified are awareness and campaign.

As well, the acknowledgement of donation theme appreciates people who have contributed funding. Still, the acknowledgement of donation and the job posting have very low levels of user engagement. Indeed, the job posting theme advertises vacancies within the organization, but high levels of user engagement are observed mainly for the awareness and others themes. As this Facebook page belonged to a mental health foundation, this explains the need for a job posting and testimonial themes. In previous research, the owner of the Facebook pages is often not known, and in some other cases, those studies have been conducted on several pages or on a page that has been generated by a user. Thus, it is possible to suggest that based on page ownership and the type of health condition, the emerging type of posts and themes would defer.

Interestingly, certain themes were given the angry emoticon. These themes include the call-toaction and awareness themes. A particular post within the call-to-action theme which generated the angry response is an article that relates to the closing down of psychiatric hospitals. Another post that evoked the use of the Angry emoticon is on how the criminal justice system response to people experiencing mental health illness. The use of the Angry emoticon clearly shows strong dissatisfaction towards these two issues, which disadvantaged people with mental health issues. However, these two posts also received other types of user engagement such as Like, Love, Share and Comment. This indicates that different users responded differently to a post. For example, with the post on how the criminal justice system response to people experiencing mental health illness, some users may appreciate such an issue being highlighted and thus, may respond with a Like, or Love. However, others may just be angry that mental health patients may receive prejudicial treatments and thus chose to respond with an Angry emoticon.

Put together, a post could have different connotations to users and in turn invoke different user engagement elements. As such, it is possible to suggest that followers of the MHFNZ Facebook page would respond by clicking different elements of user engagement based on their personal perception or reaction to a particular post. Thus, to answer the second research question (ii) how much user engagement levels do these posts garner? Our finding appears to be that the awareness and support themes have garnered the highest levels of user engagement.

In summary, prior research using different themes have garnered high levels of user engagement for posts that relate to awareness and support (AlQarni, et al., 2016). Results of this study shares the same insights in that high levels of user engagement have been observed for the awareness theme. In contrast, low levels of user engagement had been observed in prior research for posts related to services, promotion and sharing of recipes (e.g., AlQarni, et al., 2016). Results of this study did not concur with such a finding as low levels of user engagement in this study have been associated with posts on the acknowledgement of donation and the job posting themes. 


\subsection{Study Implications}

At this point, we review the study findings and provide some insights into the practical implications of these findings.

First, as the first study of its kind to analyze post characterization and user engagement levels on a mental health Facebook page, a key finding is that the top three most appealing themes to the audience for posts included those falling under the awareness, campaign and others themes. The awareness theme had been found to get the highest user engagement levels, followed by the support and advertisement theme. Comment was the most used engagement feature under the awareness theme.

Second, it is clear that the awareness theme may be used to emphasize intervention and mental health education and promotion. This means that the MHFNZ should provide more intensive awareness themes. One example is to provide information on mental health interventions on their Facebook page. This would allow for the promotion of mental health education and communication. For example, the use of brief interventions support tools (Doughty, 2005) could be made available on the Facebook page. These tools have been found to be successful in mental health promotion (World Health Organization, 2015. Thus, instead of providing awareness based on information type posts, the Mental Health Foundation Facebook page can now provide practical tool sets. These tool sets can be used by the general public to keep track of the state of their mental health. In addition, caregivers can also use this toolset to learn and enhance caregiving knowledge.

Third, as many countries start to roll out the WHO's step by step guided e-mental health interventions (Carswell, 2018), it would be timely to provide information about this e-mental health intervention program. The roll out of this program could improve accessibility for proper servicing and improve treatment coverage at a public health level (World Health Organization, 2015). The MHFNZ could also run campaigns to inform people of this tool or advertise the availability of this tool to website page followers. This tool can effectively impact treatments with depression and anxiety, which has shown to be equally beneficial even if it is conducted online v. face-to-face cognitive behavioral therapy (Carswell, 2018).

Fourth, it has been acknowledged that NZ is a land that suffers from natural disasters. Prior research has shown that there is a co-relation between going through natural disasters and the state of mental health (Fergusson, et al., 2014). Therefore, it is argued that perhaps themes in the Mental Health Foundation Facebook page would differ in comparison to other countries. Engagement levels would also differ based on posts and different type of postings would be favored by some followers but not with others. Thus, whilst earlier research indicates that posts may be different or similar based on the illness type, it can be argued that perhaps the reason for the difference could go explored further and deeper. For example, factoring in contextual information about the country, setting and culture would now have to be observed and understood to better prepare for designing posts under themes of increasing popularity and to improve the potential user engagement levels.

\section{CONCLUSION}

In this preliminary study, posts on Mental Health Foundation New Zealand Facebook page were analyzed based on post characterization and user engagement levels.

However, there are several limitations to be considered in the present study. One, this being the first research of its kind to be perform on a mental health Facebook page, a lot more still need to be done in order to verify the findings vis-à-vis results of prior research done on non-health Facebook pages or Facebook pages of other kinds of illnesses.

Second, while the results provide interesting thoughts for future design of more effective postings and what to include or not include in those postings, this study has only been limited to reviewing and visiting 100 posts. In other words, it is a preliminary and small-scale study due to limited resources. Moreover, the timeline in which data collection had taken place may have influenced themes and 
user engagement activity. Hence, in future work, the same study can be performed and extended to other mental health Facebook pages to see if similar themes and levels of user engagement occur.

Finally, it is the author's intention also to perform a large-scale study where more posts can be taken into consideration for analysis. One such future intention is to perform a detailed study within user engagement levels where comments within the posts can be further explored and analyzed indepth to better understand how followers of the page connect with posts within their social networks. It would also be interesting to review posts of mental health Facebook pages of other countries to see if the themes found in the current study aligned or might have been different. 


\section{REFERENCES}

AlMamun, M., Ibrahim, H. M., \& Turin, T. C. (2015). Social Media in Communicating Health Information: An Analysis of Facebook Groups Related to Hypertension. Preventing Chronic Disease, 12, 140265. doi:10.5888/ pcd12.140265 PMID:25633486

AlQarni, Z. A., Yunus, F., \& Househ, M. (2016). Health Information sharing on Facebook: An exploratory study on diabetes mellitus. Journal of Infection and Public Health, 9(6), 708-712. doi:10.1016/j.jiph.2016.08.015 PMID:27618634

Angie, Z. (2014). Measuring Up: Social Comparisons on Facebook and Contributions to Self-Esteem and Mental Health. Available at https://deepblue.lib.umich.edu/handle/2027.42/107346

Baker, S., Farmer, P., \& Winstley, M. (2017). The importance of public awareness campaigns for mental health. Time to Change UK. Available at https://www.time-to-change.org.uk/news/importance-public-awarenesscampaigns-mental-health

Bender, J.L., Jimenez-marroquinm, M., \& Jadad, A.J. (2013). Seeking Support on Facebook: A Content Analysis of Breast Cancer Groups. Journal of Medical Internet Research, 13(1), e16.

Bhattacharya, S., Srinivasan, P., \& Polgreen, P. (2017). Social media engagement analysis of U.S. Federal health agencies on Facebook. BMC Medical Informatics and Decision Making, 17(1), 49. Advance online publication. doi:10.1186/s12911-017-0447-z PMID:28431582

Biancovilli, P., Picanco, L., \& Jurberg, C. (2017). To read or not to read? Identifying communication patterns in three cancer related Facebook pages. Media Communication Studies.

Brailovskaia, J., \& Margraf, J. (2016). Comparing Facebook Users and Facebook Non-Users: Relationship between Personality Traits and Mental Health Variables - An Exploratory Study. PLoS One, 11(12), e0166999. Advance online publication. doi:10.1371/journal.pone.0166999 PMID:27907020

Card, K. G., Lachowsky, N., Hawkins, B. W., Jollimore, J., Baharuddin, A., \& Hogg, R. S. (2018, April-June). Predictors of Facebook User Engagement With Health-Related Content for Gay, Bisexual, and Other Men Who Have Sex With Men: Content Analysis. JMIR Public Health and Surveillance, 4(2), e38. doi:10.2196/ publichealth.8145 PMID:29625953

Carswell, K., Harper-Shehadeh, M., Watts, S., van't Hof, E., Abi Ramia, J., Heim, E., Wenger, A., \& van Ommeren, M. (2018). Step-by-Step: A new WHO digital mental health intervention for depression. mHealth, 2018(4), 34. doi:10.21037/mhealth.2018.08.01 PMID:30225240

Chamber, A. (2010). Mental Illness and the developing world. The Guardian. Available at https://www. theguardian.com/commentisfree/2010/may/10/mental-illness-developing-world

Clark, T., Fleming, T., \& Bullen, P. (2013). Youth'12 Overview: The health and wellbeing of New Zealand secondary school students in 2012. The University of Auckland. Available from https://www.fmhs.auckland. ac.nz/assets/fmhs/faculty/ahrg/docs/2012-overview.pdf

Close, J. (2016). The doctor won't see you now: on NZ's shameful mental health wait time. The Spinoff. Available at https://thespinoff.co.nz/society/19-08-2016/the-doctor-wont-see-you-now-on-nzs-shameful-mental-healthwait-times/

De la Torre-Diez, I., Diaz-Pernas, F. J., \& Anton-Rodrequez, M. (2012). A Content Analysis of chronic diseases social groups on Facebook and Twitter. Telemedicine Journal and e-Health, 18(6), 404-408. doi:10.1089/ tmj.2011.0227 PMID:22650380

Doughty, C. (2005). The effectiveness of mental health promotion, prevention and early intervention in children, adolescents and adults A critical appraisal of the literature. Available at http://nzhta.chmeds.ac.nz/publications/ finalmhp7_05pt1.pdf

Duggan, M., Ellison, N. B., Lampe, C., Lenhart, A., \& Madden, M. (2016). Social media update 2014. Pew Research Centre. Available at https://www.pewinternet.org/2016/11/11/social-media-update-2016/

Egan, K. (2017). The difference between Facebook, Twitter, Linkedin, YouTube, \& Pinterest. Available at https:// www.impactplus.com/blog/the-difference-between-facebook-twitter-linkedin-google-youtube-pinterest 
Farahania, H., Kazemi, Z., Aghamohamadib, S., Bakthirar, F., \& Ansarid, M. (2011).. . Procedia: Social and Behavioral Sciences, 28, 811-814. doi:10.1016/j.sbspro.2011.11.148

Farmer, A.D., Bruckner Holt, C.E., Cool, M.J., \& Hearing, S.D. (2009). Social networking sites: a novel portal for communication. Postgrad Med J., 85(1007), 455-459.

Fergusson, D. M., Horwood, L. J., Boden, J. M., \& Mulder, R. T. (2014, September). Impact of a major disaster on the mental health of a well-studied cohort. JAMA Psychiatry, 71(9), 1025-1031. doi:10.1001/ jamapsychiatry.2014.652 PMID:25028897

Frost, R. L., \& Rickwood, D. J. (2017). A systematic review of the mental health outcomes associated with Facebook use. Computers in Human Behavior, 76(November), 576-600. doi:10.1016/j.chb.2017.08.001

Giustini, D., Ali, S. M., Fraser, M., \& Boulos, N. M. K. (2018). Effective uses of social media in public health and medicine: A systematic review of systematic reviews. Online Journal of Public Health Informatics, 10(2), e215. doi:10.5210/ojphi.v10i2.8270 PMID:30349633

Goldenberg, M. (2016). How Increased Fundraising And Research Dollars for Mental Health Can Save Live, The Blog. Huffington Post. Available at https://www.huffingtonpost.com/dr-matt-goldenberg-do-/how-increasedfundraising_b_11079332.html

Health and Disability Commissioner. (2019). New Zealand's Mental Health and Addiction Services: Monitoring indicator update 2017 \& 2017/18. Health and Disability Commissioner.

King, M. (2017). Mike King: New Zealand's mental health system is 'broken'. The New Zealand Herald. Available at https://www.nzherald.co.nz/nz/news/article.cfm?c_id=1\&objectid=11891275

Kordzadeh, N., \& Warren, J. (2013). Toward a typology of health 2.0 collaboration platforms and websites. Health and Technology, 3(1), 37-50. doi:10.1007/s12553-013-0043-x

Lee, J., \& Hong, I. B. (2016). Predicting positive user responses to social media advertising: The roles of emotional appeal, informativeness, and creativity. International Journal of Information Management, 36(3), 360-373. doi:10.1016/j.ijinfomgt.2016.01.001

Lefebvre, R. (2016). How to use Facebook's new Reactions emojis the right way. Available at https://www. cultofmac.com/414248/how-to-use-facebook-reactions-the-right-way/

McConnel, G. (2016). The highest rate of teen suicide in the developed world. Stuff Health. Available at https:// www.stuff.co.nz/national/health/85305366/the-highest-rate-of-teen-suicide-in-the-developed-world

McCool, M. (2016). Suicide and mental health: NZ's quiet crisis. Stuff Nation. Available at http://www.stuff.co.nz/ stuff-nation/assignments/share-your-news-and-views/14884954/Suicide-and-mental-health-NZs-quiet-crisis

Mental Health Foundation. (2020). Available at https://www.mentalhealth.org.nz/

Mental Health Foundation of New Zealand. (n.d.a). About. Available at https://www.mentalhealth.org.nz/home/ about/

Mental Health Foundation of New Zealand. (n.d.b). Facebook page. Available at https://www.facebook.com/ mentalhealthfoundationNZ/

Menzies, R., Gluckman, P \& Poulton, R. (2020). Youth Mental Health in Aotearoa New Zealand: Greater Urgency Required September 2020. Academic Press.

Ministry of Health. (2013). New Zealand Health Survey: Annual update of key findings 2012/13. Ministry of Health.

Nazzal, Z., Rabee, H., Ba' ara, M., \& Berte, D. (2018). Excessive Facebook use and physical and mental health risks in the occupied Palestinian territory: A cross sectional study. Lancet, 291(Special Issue), S38. doi:10.1016/ S0140-6736(18)30363-5

Office of the Prime Minister's Science Advisory Committee. (2011). Improving the transition. Reducing social and psychological morbidity during adolescence. Office of the Prime Minister's Science Advisory Committee 2011. Available from: https://www.pmcsa.org.nz/wp-content/uploads/Improving-the-Transition-report.pdf 
Park, H., Rodgers, S., \& Stemmle, J. (2013). Health Organization's Use of Facebook for Health Advertising and Promotion. Journal of Interactive Advertising, 12(1), 62-77. doi:10.1080/15252019.2011.10722191

Perrin, A. (2015). Social media usage:2002-2015. Pew Research Centre. Available at https://www.pewinternet. org/files/2015/10/PI_2015-10-08_Social-Networking-Usage-2005-2015_FINAL.pdf

Ritchie, H., \& Roser, M. (2018). Mental Health, Out World In Data. Available at https://ourworldindata.org/ mental-health

Sampogna, G., Bakolis, I., Evans-Lacko, S., Robinson, E., Thornicroft, G., \& Henderson, C. (2017). The impact of social marketing campaigns on reducing mental health stigma: Results from the 2009-2014 Time to Change programme. European Psychiatry, 40, 116-122.

Syn, S. Y. (2015). A Comparison of User Engagement with the CDC Facebook Page During Health Crisis and Ordinary Periods. Proceedings of the 17th International Conference on Asia-Pacific Digital Libraries, 9469 , 258-263. doi:10.1007/978-3-319-27974-9_27

Torgovnick, K. (2008). Why Do The Mentally Ill Die Younger? TIME Magazine. Available at http://content. time.com/time/health/article/0,8599,1863220,00.html\#ixzz26AvjkszJ

Wiggins, A. (2017). Mental health funding 'distressing. New Zealand Herald. Available at https://www.nzherald. co.nz/nz/budget-2017-mental-health-funding-distressing/XWOIC2L73VLIMQYVZZQXSA22T4/

World Health Organization. (2020). World Mental Health Day: an opportunity to kick start a massive scale up in investment in mental health. Available at https:/www.who.int/news/item/27-08-2020-world-mental-healthday-an-opportunity-to-kick-start-a-massive-scale-up-in-investment-in-mental-health

World Health Organization. (2015). Comparative effectiveness of different formats of psychological treatments for depressive disorder. Available from: https://www.who.int/mental_health/mhgap/evidence/depression/q8/en/

Xie, K., \& Lee, Y.-J. (2015). Social Media and Brand Purchase: Quantifying the Effects of Exposures to Earned and Owned Social Media Activities in a Two-Stage Decision Making Model. Journal of Management Information Systems, 32(2), 204-238. doi:10.1080/07421222.2015.1063297

Zhang, Y., He, D., \& Sang, Y. (2013, June). Facebook as a platform for Health Information and Communication: A Case Study of a Diabetes Group. Journal of Medical Systems, 37(3), 9942. doi:10.1007/s10916-013-9942-7 PMID:23588823

Zhang, Y., \& Wildemuth, B. M. (2005). Qualitative Analysis of Content. Analysis, 1(2), 1-12. 